\title{
Correspondence
}

We welcome letters to the Editor concerning articles which have recently been published. Such letters will be subject to the usual stages of selection and editing; where appropriate the authors of the original article will be offered the opportunity to reply.

Letters should normally be under 300 words in length, double-spaced throughout, signed by all authors and fully referenced. The edited version will be returned for approval before publication.

\section{The tourniquet in total knee arthroplasty}

Sir

We read with interest the article by Wakankar et al ${ }^{1}$ in the January 1999 issue entitled 'The tourniquet in total knee arthroplasty'.

There are several points which we wish to raise. It is unclear how many surgeons, and of what grade, operated and where the surgery was performed. It is not stated what problems were encountered with bleeding when a tourniquet was not used. Although they conclude that the tourniquet can be used satisfactorily, more wound problems were observed in this group, including one wound still leaking at six weeks.

Concern was expressed about haemostasis and the ability to create an appropriate bone surface for applying cement when a tourniquet was not used. A combination of regional anaesthesia, exposure of the joint with the knee flexed and the use of intraosseous suction applied within $1 \mathrm{~cm}$ of the cut bone surfaces with lavage, creates an ideal environment and considerably reduces airborne debris.

If a tourniquet is used the cuff pressure should be restricted to $100 \mathrm{mmHg}$ above the systolic pressure. ${ }^{2}$ Its use is strongly contraindicated in the presence of diabetes, peripheral vascular disease, rheumatoid disease, previous thromboembolism, active malignancy, multiply scarred legs, obese thighs and for revision surgery.

Since so many authors have attributed complications to the use of the tourniquet, such as nerve paralysis, vascular injury, circulatory changes on exsanguination with cardiac or respiratory problems, cardiac arrest, pulmonary oedema, increased rates of DVT and, recently, increased rates of embolism, ${ }^{3}$ does it not seem that the best practice is to avoid its use? We have shown that knee replacement surgery can now be performed with confidence without the use of the tourniquet and that many of the local and systemic complications of operating in a bloodless field can be avoided. ${ }^{4}$

K. S. EYRES, MD, FRCS Orth

I. SHARPE, FRCS

Princess Elizabeth Hospital

Exeter, UK.

A. ABDEL-SALAM, FRCS

Nuneaton, UK.
1. Wakankar HM, Nicholl JE, Koka R, D'Arcy JC. The tourniquet in total knee arthroplasty: a prospective, randomised study. J Bone Joint Surg [Br] 1999;81-B:30-3.

2. Worland RL, Arredondo J, Angles F, Lopez-Jimenez F, Jessup DE. Thigh pain following tourniquet application in simultaneous bilateral total knee replacement arthroplasty. J Arthroplasty 1997;12:848-52.

3. Parmet JL, Horrow JC, Berman AT, et al. The incidence of large venous emboli during total knee arthroplasty without pneumatic tourniquet use. Anesth Analg 1998;87:439-44.

4. Abdel-Salam A, Eyres KS. Effects of tourniquet during total knee arthroplasty: a prospective, randomised trial. J Bone Joint Surg $[\mathrm{Br}]$ 1995;77-B:250-3.

Authors' reply:

Sir,

We thank Messrs Eyres, Abdel-Salam and Sharpe for their letter and have noted their comments with interest.

Our study ${ }^{1}$ had almost the same structure as that of AbdelSalam and Eyres ${ }^{2}$, but we used many strict exclusion criteria for the selection of patients such as rheumatoid arthritis, diabetes, etc, to reduce the confounding factors. Our results do not match those of Abdel-Salam and Eyres and the selection of patients may be one of the reasons. Both studies had small numbers of patients with the obvious limitations as a result.

All our patients were under the care of one consultant in one hospital and there were five surgeons (including two registrars and two associate specialists) following the predecided protocol. All trainee surgeons were supervised. When operating without a tourniquet surgeons considered bleeding to be a nuisance in seven knees and noted moderate to heavy bleeding in the form of constant oozing in six. In none of these cases did the tourniquet need to be applied and the surgery was completed satisfactorily.

All wounds had healed at the final review at four months. The patient with a small leaking wound had no evidence of deep infection and in our view this case does not raise concern regarding the use of a tourniquet especially since the wound had healed at four months. We would again draw attention to the fact that our patients had to satisfy exclusion criteria thereby reducing confounding factors. We entirely agree that surgery can be safely performed without a tourniquet especially in the presence of the many risk factors quoted; all patients with such problems were excluded from our study. In their absence, however, we have found it safe to use a tourniquet.

J. C. D'ARCY, FRCS

H. M. WAKANKAR, MCh Orth, FRCS Orth

Eastbourne District General Hospital

Eastbourne, UK.

1. Wakankar HM, Nicholl JE, Koka R, D'Arcy JC. The tourniquet in total knee arthroplasty: a prospective, randomised study. J Bone Joint Surg [Br] 1999;81-B:30-3.

2. Abdel-Salam A, Eyres KS. Effects of tourniquet during total knee arthroplasty: a prospective, randomised study. J Bone Joint Surg [Br] 1995;77-B:250-3

Sir,

We read with interest the recent study by Wakankar et $\mathrm{al}^{1}$ in the January 1999 issue entitled 'The tourniquet in total knee arthroplasty'. The very low incidence of deep-vein thrombosis (DVT) in this study $(1 / 51 ; 1.96 \%)$ is quite remarkable when compared with the $50 \%$ to $84 \%$ reported in other series. ${ }^{2-4}$ Patients undergoing
(C)1999 British Editorial Society of Bone and Joint Surgery 0301-620X/99/510316\$2.00

J Bone Joint Surg [Br] 1999;81-B:932-5. 
total knee replacement (TKR) are at increased risk of popliteal and calf-vein thrombosis (CVT). Studies show that $12 \%$ to $32 \%$ of CVT may propagate, ${ }^{5-7}$ which increases the risk of pulmonary embolism. Duplex ultrasonography is still unreliable for diagnosing CVT and its use in this study may be partially responsible for the low incidence of DVT reported, which jeopardises the validity of the results and conclusions. We suggest that a more reliable diagnostic tool such as contrast phlebography should have been used.

Although the only DVT reported in the study was in the tourniquet group, and the difference was reported as insignificant, no mention was made of the numbers in either group.

The application of a tourniquet may impair venous drainage, damage the venous endothelium and confine coagulation reactants to below the tourniquet. Clinical evidence of the risk of DVT with a tourniquet in TKR is still inconclusive. ${ }^{8-9}$ The release of large venous emboli after deflation of a tourniquet during cemented intramedullary TKR has been shown to increase pulmonary vascular resistance and may contribute to fatal or nearly fatal intraoperative cardiac arrest. ${ }^{10-12}$ Moreover, Parmet et al $^{13}$ have shown that compared with TKR without a tourniquet, the use of a tourniquet places patients at a 5.33-fold greater risk of large emboli. We are concerned that, pending the availability of irrefutable evidence, based on adequate numbers and robust methodology, it may be dangerous to ignore the risk of venous thrombosis and potential fatal embolism associated with the continued use of a tourniquet in TKR.

O. AGU, FRCS

D. BAHER, PhD, FRCS

G. HAMILTON, FRCS

Royal Free Hospital

London, UK.

1. Wakankar HM, Nicholl JE, Koka R, D'Arcy JC. The tourniquet in total knee arthroplasty: a prospective, randomised study. J Bone Joint Surg [Br] 1999;81-B:30-3.

2. Stulberg BN, Insall JN, Williams GW, Ghelman B. Deep vein thrombosis following total knee replacement: an analysis of six hundred and thirty-eight arthroplasties. J Bone Joint Surg [Am] 1984; 66-A:194-201.

3. Lotke PA, Faralli VJ, Orenstein EM, Ecker ML. Blood loss after total knee replacement: effect of tourniquet release and continuous passive motion. J Bone Joint Surg [Am] 1991;73-A:1037-40.

4. Merli GJ. Deep vein thrombosis and pulmonary embolism prophylaxis in orthopaedic surgery: update. Med Clin North Am 1993;77: 397-411.

5. Lohr JM, Kerr TM, Lutter KS, et al. Lower extremity calf thrombosis: to treat or not to treat? (published erratum appears in $J$ Vasc Surg 1992;15:323). J Vasc Surg 1991;14:618-23.

6. O'Shaughnessy AM, Fitzgerald DE. The value of duplex ultrasound in the follow-up of acute calf vein thrombosis. Int Angiol 1997;16: 142-6.

7. Lohr JM, James KV, Deshmukh RM, Hasselfeld KA, Allastair B. Karmody Award: calf vein thrombi are not a benign finding. Am $J$ Surg 1995; 170:86-90.

8. Abdel-Salam A, Eyres KS. Effect of tourniquet during total knee arthroplasty: a prospective, randomised trial. J Bone Joint Surg [Br] 1995;77-B:250-3.

9. Harvey EJ, Leclerc J, Brooks CE, Burke DL. Effect of tourniquet use on blood loss and incidence of deep vein thrombosis after total knee arthroplasty. J Arthroplasty 1997;12:291-6.

10. Parmet JL, Berman AT, Horrow JC, Harding S, Rosenburg H. Thromboembolism coincident with tourniquet deflation during total knee arthroplasty. Lancet 1993;341:1057-8.

11. McGrath BJ, Hsia J, Epstein B. Massive pulmonary embolism. Anesthesiology 1991;74:618-20.

12. Messahel FM. Incidence of pulmonary embolism in total knee arthroplasty. Middle East J Anesthesiol 1991;11:187-92.

13. Parmet JL, Horrow JC, Berman AT, et al. The incidence of large venous emboli during total knee arthroplasty without pneumatic tourniquet use. Anesth Analg 1998;87:439-44.
Authors' reply:

Sir,

We thank Messrs Agu, Baher and Hamilton for their comments. Calf-vein thrombosis is a very controversial subject and there are reports both against ${ }^{1-3}$ and in favour ${ }^{4-8}$ of active treatment. Lotke, Steinberg and Ecker ${ }^{9}$ suggest that calf thrombi after total joint arthroplasty do not place a patient at risk.

When planning this study, we were limited to the use of Duplex ultrasonography as a method of diagnosing deep-vein thrombosis (DVT). Of the 77 patients in our study $51(66 \%)$ had Duplex ultrasonography before and after operation; these included 25 and 26 patients from each group.

Many hospitals, including ours, have now given up the use of venous phlebography for diagnosing DVT and routinely use Duplex ultrasonography. This has the obvious implication that calf-vein thrombosis would not be adequately diagnosed and by default not treated. Whether this policy has led to increased numbers of deaths from pulmonary embolism remains unknown. In our study, three patients died 16 weeks to 14 months after surgery. Two had had surgery without a tourniquet. All three had had Duplex ultrasonography postoperatively which did not show evidence of DVT. Our small study did not show any serious consequences with the use of a tourniquet in total knee replacement in a controlled group of patients which satisfied exclusion criteria.

We entirely accept that contrast venography is the optimum method of diagnosis of DVT, especially in the calf. There have been several studies on this subject but reliable evidence concerning calf DVT is not forthcoming in the absence of a multicentre trial of a large number of patients with minimal confounding factors. Prophylaxis for DVT in our study included the use of lowdose Warfarin for four weeks and foot pumps for a variable postoperative period. We are not ignoring the risk of DVT and pulmonary embolism but we failed to confirm the findings of Parmet et $\mathrm{al}^{10}$ in our small study.

J. C. D'ARCY, FRCS

H. M. WAKANKAR, MCh Orth, FRCS Orth

Eastbourne District General Hospital

Eastbourne, UK.

1. Hirsh J, Lensing AWA. Natural history of minimal calf deep vein thrombosis. In: Bernstein EF, ed. Vascular diagnosis. Fourth ed. St Louis: CV Mosby, 1993:779-81.

2. Meibers DJ, Baldridge ED, Ruoff BA, et al. The significance of calf muscle vein thrombosis. J Vasc Technol 1988;12:143-8.

3. Menzoian JO, Sequeria JC, Doyle JE, et al. Therapeutic and clinical course of deep venous thrombosis. Am J Surg 1983;146:581-5.

4. Haas SB, Tribus CB, Insall JN, Becker MW, Windsor RE. The significance of calf thrombi after total knee arthroplasty. J Bone Joint Surg [Br] 1992;74-B:799-802.

5. Giachino A. Relationship between deep-vein thrombosis in the calf and fatal pulmonary embolism. Can J Surg 1988;31:129-30.

6. Philbrick JT, Becker DM. Calf deep vein thrombosis: a wolf in sheep's clothing? Arch Intern Med 1988;148:2131-8.

7. Oishi CS, Grady-Benson JC, Otis SM, Colwell CW, Walker RW. The clinical course of distal deep venous thrombosis after total hip and knee arthroplasty, as determined with Duplex ultrasonography. $J$ Bone Joint Surg [Am] 1994;76-A:1658-63.

8. Lohr JM, James KV, Deshmukh RM, Hasselfeld KA. Calf vein thrombi are not a benign finding. Am J Surg 1995;175:86-90.

9. Lotke PA, Steinberg ME, Ecker ML. Significance of deep venous thrombosis in the lower extremity after joint arthroplasty. Clin Orthop 1994;299:25-30.

10. Parmet JL, Horrow JC, Berman AT, et al. The incidence of large venous emboli during total knee arthroplasty without pneumatic tourniquet use. Anesth Analg 1998;87:439-44. 
Sir,

We read with interest the article by Wakankar et al ${ }^{1}$ in the January 1999 issue entitled 'The tourniquet in total knee arthroplasty'. We do not agree with their finding of the similarity of the intensity of early postoperative pain between those with the tourniquet applied and those without. We believe that tourniquet-induced limb ischaemia significantly increases the intensity of early postoperative pain in orthopaedic procedures in both the upper and lower limbs. ${ }^{2,3}$ Ischaemia induced by use of a tourniquet for longer than one hour leads to ultrastructural damage to the skeletal muscle distal to the cuff, which may be the first step towards muscular atrophy. ${ }^{4,5}$ This may explain the early decrease in the range of movement due to delayed recovery of muscle in the patients who had a tourniquet.

H. ÖMEROĞLU, MD

S. SEBER, MD

Osmanagazi University Hospital

Eskisehir, Turkey.

1. Wakankar HM, Nicholl JE, Koka R, D'Arcy JC. The tourniquet in total knee arthroplasty: a prospective, randomised study. J Bone Joint Surg [Br] 1999;81-B:30-3.

2. Ömeroğlu H, Günel $\mathbf{U}$, Biçimoğlu A, et al. The relationship between the use of tourniquet and the intensity of postoperative pain in surgically treated malleolar fractures. Foot Ankle Int 1997;18: 798-802.

3. Ömeroğlu H, Uçaner A, Tabak AY, et al. The effect of using a tourniquet on the intensity of postoperative pain in forearm fractures: a randomised study in 32 surgically treated patients. Int Orthop 1998; 22:369-73

4. Appel HJ, Glöser S, Duarte JAR, Zellner A, Soares JMC. Skeletal muscle damage during tourniquet-induced ischaemia: the initial step towards atrophy after orthopaedic surgery? Eur J Appl Physiol 1993; 67:342-7.

5. Ömeroğlu H, Erdoğan D, Ömeroğlu S, Günel U, Biçimoğlu A. Ultrastructural analysis of the alterations in skeletal muscle during tourniquet application on extremities (In Turkish). Acta Orthop Traumatol Turc 1997;31:323-6.

\section{Authors' reply:}

Sir

We thank Drs Ömeroğlu and Seber for their interest in our paper.

Pain is difficult to quantify and the requirement of analgesics is just one of the many inadequate ways of judging it. The number of patients in the study is small and although the average requirement for analgesics in the group with a tourniquet was higher, we found no statistical difference between the two groups. Dr Ömeroğlu may well be correct in suggesting that tourniquet-induced ischaemia increases the intensity of early postoperative pain. The early decrease in the range of movements with the use of a tourniquet is perhaps due to some muscle injury, possibly at ultrastructural level. The final outcome showed no difference in knee flexion in the two groups, however, suggesting that there was full muscle recovery from any temporary damage.

\section{J. C. D'ARCY, FRCS}

H. M. WAKANKAR, MCh Orth, FRCS Orth

Eastbourne District General Hospital

Eastbourne, UK.

\section{Acute fractures of the scaphoid}

Sir,

I write with reference to the paper in the January 1999 issue by Hambidge et al $^{1}$ entitled 'Acute fractures of the scaphoid'.

The authors found extension to be significantly less in those wrists which had been immobilised in flexion and recommend that these fractures be splinted in extension. The difference in wrist extension between the groups is about $10^{\circ}$, which matches the normal difference in wrist extension between the right and left sides. $^{2}$ There is no information as to whether the left or right scaphoids were fractured, but if most of the patients immobilised in extension had left-sided fractures, and those with immobilisation in flexion had right-sided injuries, then the difference will not be significant. It is of interest that the authors did not find a significant difference between the groups with reference to wrist flexion, and there is no significant difference in wrist flexion between the sides in normal subjects.

The authors conclude that "immobilisation of the wrist is important for union, rather than the position". In my opinion, the important factor is the immobilisation of the scaphoid, not the wrist. ${ }^{3}$

I. GÜNAL, MD

Dokuz Eylül University School of Medicine

Balçova, Izmir, Turkey.

1. Hambidge JE, Desai VV, Schranz PJ, Compson JP, Davis TRC, Barton NJ. Acute fractures of the scaphoid: treatment by cast immobilisation with the wrist in flexion or extension? J Bone Joint Surg [Br] 1999;81-B:91-2.

2. Günal I, Köse N, Erdoğan O, Göktürk E, Seber S. Normal range of motion of the joints of the upper extremity in male subjects with special reference to side. J Bone Joint Surg [Am] 1996;78-A: $1401-4$.

3. Günal I, Öztuna V, Seber S. Trapeziolunate external fixation for scaphoid fractures: an experimental and clinical study. J Hand Surg [Br] 1994;19-B:759-62.

Author's reply:

Sir,

I thank Dr Günal for his comments and point out that, as mentioned in our paper, the two treatment groups were well matched for side of injury.

Of the 121 fractures, 58 occurred in the dominant wrist and the mean wrist extension in the uninjured wrists was $73^{\circ}(\mathrm{SD}=10)$. When the dominant and non-dominant wrist injuries were analysed separately, the significant reduction in extension was still detected. Furthermore, for the 11 injured wrists with less than $45^{\circ}$ extension at follow-up, the mean wrist extension in the contralateral uninjured wrist was $63^{\circ}(\mathrm{SD}=15)$. We thus consider that the observed reduction in wrist extension after treatment of scaphoid fractures in a Colles'-type cast which holds the wrist flexed, is an accurate observation.

We agree that in order to achieve union of scaphoid fractures it is vital to immobilise the scaphoid bone. In our opinion the simplest, safest and most cost-effective method is to place the wrist in a plaster cast.

T. R. C. DAVIS, FRCS

Queen's Medical Centre

Nottingham, UK.

\section{Salvage of the head of the radius after fracture-dislocation of the elbow}

Sir,

I read with interest the article in the March 1999 issue by Patel and Elliott ${ }^{1}$ entitled 'Salvage of the head of the radius after fracture-dislocation of the elbow' and congratulate them on their method using a tricortical autograft.

Fracture-dislocations of the elbow can be associated with injuries to the insertion of the biceps tendon. Since the bicipital 
tuberosity is just distal to the radial neck, it appears to have been involved in the original injury. It is also noted that this 61-year-old patient was able to obtain a useful arc of elbow flexion and extension, yet lacked $80^{\circ}$ of forearm supination.

What was the condition of the biceps at the time of surgery? Was it reattached to the tricortical autograft? If not, this may explain the patient's loss of forearm rotation, or is this due to the ipsilateral fracture of the distal radius?

\section{M. TOROSIAN, MD}

Fox Valley Orthopaedic Institute

Geneva, Illinois, USA.

1. Patel VR, Elliott DS. Salvage of the head of the radius after fracturedislocation of the elbow. J Bone Joint Surg [Br] 1999;81-B:306-8.

\section{Authors' reply:}

Sir,

Thank you for the opportunity to reply to Dr Torosian's letter. The patient which we described had a horrendous injury to the elbow and at the time of surgery the priority was to regain some stability at the elbow. No specific attempt was made to identify the biceps tendon.

At follow-up, rupture of the distal tendon of the biceps was not clinically apparent. We surmise that the limitation of rotation was partly due to scarring around the proximal radius and partly to the fracture of the distal radius.

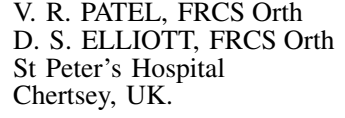

\section{The pathology of bone allograft}

Sir,

We read with interest the article in the March 1999 issue entitled

'The pathology of bone allograft' by Palmer et al. ${ }^{1}$ We have found similar results in a study of 123 iliac bone biopsies from potential bone allograft donors using light microscopy and histomorphometric analysis. Approximately $10 \%$ of biopsies showed severe osteoporosis. There was one case of a myeloproliferative disorder and one of bone-marrow aplasia. These conditions were present despite routine screening methods such as those outlined in the paper by Palmer et al. Although the clinical implications of transplanting severely osteoporotic bone are uncertain and there is debate as to what extent marrow abnormalities survive processing in a bone bank, we agree with the conclusion that occult findings are common and that histological examination of bone-allograft donors should be included in routine screening procedures by bone banks.

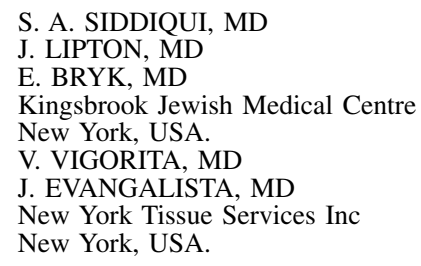

1. Palmer SH, Gibbons CLMH, Athanasou NA. The pathology of bone allograft. J Bone Joint Surg [Br] 1999;81-B:333-5.

\section{Author's reply:}

Sir,

We thank Dr Siddiqui and his colleagues for their comments and would be interested to see their results on the histological examination of their bone biopsy specimens. It is obvious that occult findings of unsuspected pathology are not uncommon and that some form of histological screening is necessary to ensure safe standards of bone transplantation.

\section{S. H. PALMER, FRCS}

Nuffield Orthopaedic Centre Oxford, UK. 